\title{
A POSSÍVEL INTERFACE ENTRE EDUCAÇÃO FORMAL E NÃO-FORMAL: A ESCOLA COMO INSTRUMENTALIZADORA NO PROCESSO DE EMANCIPAÇÃO DA COMUNIDADE E A INTERVENÇÃO NA REALIDADE SOCIAL
}

\author{
Erika Germanos ${ }^{1}$ \\ Carlos Hiroo Saito ${ }^{2}$
}

RESUMO: O texto faz uma discussão sobre a relação entre a ampliação do acesso à escola e o caráter da escola enquanto instrumentalizadora do interesse emancipatório das camadas populares. Historicamente, a ampliação da consciência do direito à escola nas últimas décadas está totalmente associada à luta pela melhoria das condições básicas de sobrevivência, ou seja, as condições sociais, econômicas e políticas. O que queremos ressaltar é que não se pode isolar a escola do contexto histórico e dos movimentos sociais, sob pena de proceder a uma análise parcial e fragmentada do processo educacional. $O$ fortalecimento da escola enquanto um ente a serviço dos interesses populares passa justamente pela luta para abertura dos muros da escola à comunidade. Propomos pensar nos indivíduos na sua integralidade levando em consideração os processos de humanização. Para tanto, parcerias entre a educação formal e educação não-formal representam um caminho fértil para promover o desenvolvimento humano. Assim é necessário que se faça da escola um espaço de transformação e que as escolas funcionem como centros de referência nas suas regiões de influência.

Palavras-chave: Educação formal; Educação não-formal; Lutas populares; Interesse emancipatório.

ABSTRACT: The text presents a discussion of the relationship between the expansion of access to education and the nature of the school as knowledge support to the emancipatory interest of the working classes. Historically, the increased awareness of the right to schooling in recent decades is fully associated with the struggle for the improvement of the basic survival, in their social, economic and political aspects. What we want to emphasize is that one can not isolate the school from the historical context and social movements, failing to carry out a partial and fragmented analysis of the educational process. The strengthening of the school as an entity to serve the interests of the people depends on the struggle to open the walls of the school to community. We propose to think individuals as a whole taking into account the processes of humanization. Therefore, partnerships between formal and nonformal education represents a fertile way to promote human development. So it is necessary to make the school a place of transformation and that schools function as referral centers in their regions of influence.

Keywords: Formal education; Non-formal education; Popular struggles; Emancipatory interest.

\footnotetext{
${ }^{1}$ Graduação em Ciências Biológicas pela Universidade Federal de Uberlândia (UFU). Mestrado em Biodiversidade Animal pela Universidade Federal de Santa Maria (UFSM). Doutoranda em Educação pela UFU. Docente do Centro Universitário de Brasília (UniCEUB).

2 Professor efetivo (Classe Associado 4) do Departamento de Ecologia da Universidade de Brasília (UnB). Docente do Programa de Pós-Graduação em Desenvolvimento Sustentável da UnB.
} 


\section{INTRODUÇÃO}

Quando se refere à educação ou aprendizagem nosso imaginário, na maioria das vezes, nos remete ao modelo de escola e sua organização formal. O conceito de educação parece estar sempre associado ao ou confundido com o conceito de escola. A escola tem sido reconhecida historicamente como lócus de acesso ao saber sistematizado e por isso alvo de disputas políticas e lutas das camadas populares pela universalização das oportunidades de ingresso na educação básica. Os movimentos sociais nos anos 70-80 exerceram forte influência na formação da consciência popular pelo direito à educação básica, pela democratização e aumento do acesso à escola pública, na esteira das lutas pela ampliação de direitos sociais nas áreas urbanas. Essa relação é bastante reconhecida e apontada em várias pesquisas, dissertações e teses, especialmente quando é remetido à América Latina onde ocorreu uma intensa ocupação desordenada nas áreas urbanas, promovendo um estado de caos. Kowarick (1983) analisa as desigualdades e exclusão sociais em relação às práticas rotineiras e as dificuldades de acesso a bens de consumo coletivos de responsabilidade direta dos governos, como transporte, saúde, educação e moradia desenvolvendo o conceito de espoliação urbana. Assim, este autor propõe inverter a lógica da culpa sobre os modos de ocupação das áreas urbanas associada aos cidadãos, além de desvelar a matriz de desigualdade típica do capitalismo existentes nas cidades. Lúcio Kowarick discute ainda que não são apenas as carências vividas pela população que promovem a passagem para as mobilizações sociais, mas quando vivenciadas em contextos específicos. E é nesse período de democratização que emergem vários movimentos sociais relacionados a demandas por transporte, saúde, educação e moradia no país. Pois, quando as condições materiais objetivas provocam inquietação nas camadas populares estas passam a enxergar a educação como sendo um direito, juntamente com saúde, moradia, segurança e assim a necessidade real de inserção social, política e educacional se torna pauta nos movimentos sociais.

A realidade histórica mostra que a República se omitiu na fundação e na melhoria das escolas públicas brasileiras. Desde o início do regime democrático não foi capaz de estender a educação para todos e essa realidade dificultou muito o desenvolvimento da escola pública e democrática no país (TEIXEIRA,1999). Na visão de Florestan Fernandes (1960) as camadas populares deveriam se unir aos 
defensores do ensino público na luta pela democracia no contexto educacional. Este autor considerava importante para a formação e conscientização para vida em sociedade a expansão da escola primária, pois representava a possibilidade de oportunizar aos indivíduos uma formação consciente, crítica e que promovesse a emancipação social e esta realidade repercutiria na fundamentação da democracia no país. O ensino precisava sofrer mudanças em relação ao alcance e a qualidade para que as escolas tivessem condição de absorver a população em idade escolar e assim terem condição de criar um tipo de ensino útil à preparação do homem para uma sociedade na qual todos precisam participar responsavelmente do funcionamento das instituições políticas democráticas.

\section{AMPLIAÇÃO DO ACESSO OU MAIS QUE ISSO?}

Portanto, não se trata apenas de mera luta pela ampliação do acesso à escola; essa luta traz em seu bojo também uma reivindicação sobre o caráter da escola. Ou seja, ela revela a necessária vinculação entre as finalidades da educação e o contexto social e histórico em que determinadas missões são definidas para a escola.

Em Ponce (1991) há uma análise sobre a educação e suas finalidades no âmbito das relações econômico-políticas buscando as bases do papel social e político que a educação desempenha em cada época e lugar. Assim as finalidades educativas se originam na natureza das estruturas sociais vigentes que compõem a sociedade atendendo a seus interesses e necessidades em um dado tempo. $\mathrm{O}$ autor conclui que a organização econômica é que confere as características do ideal pedagógico e junto a esse trazem as concepções de homem e mundo estando ou não explícitas, o que em certa medida é uma visão muito estruturalista e pouco dialética, pois apresenta as contradições como sufocadas e as possibilidades de mudança como mera ilusão, muito à semelhança da visão althusseriana de Aparelhos Ideológicos de Estado (AIE) (ALTHUSSER, 1980). Os AIE funcionam, pois, a partir de uma ideologia dominante, a da classe dominante e mesmo que existam dentro destes sistemas diversidades e contradições a ideologia pelo qual funcionam é unificada impossibilitando as transformações. Vale ressaltar que os Aparelhos Ideológicos do Estado não são apenas o alvo, mas também o lócus de lutas de classes. 
Nesse contexto ressaltamos que a ampliação da consciência do direito à escola nas últimas décadas está totalmente associada à luta pela melhoria das condições básicas de sobrevivência, ou seja, as condições sociais, econômicas e políticas. Para Arroyo (2003) a expansão da escola básica aconteceu não apenas porque se exige uma maior escolarização para se conseguir um trabalho, ou porque houve uma mudança de consciência social apenas, mas pela reeducação dessa consciência provocada pelas pressões populares. O autor ainda afirma que os movimentos sociais marcantes nas décadas de 70-80 exerceram papel pedagógico importante, pois mesmo em outras instâncias que não a dos sindicatos ou movimentos operários a luta pelos direitos educaram a população de alguma forma que aprendeu a reivindicar e buscar condições mais dignas de existência. Para ele é também a sensibilidade humana que pressiona pelo direito a dar dignidade aos filhos.

Assim, é legítimo considerar aqui essas lutas populares por melhores condições de vida como processos educativos não-formais de dimensões coletivas.

Cabe então reconhecer que as experiências não-formais de educação se aproximam muito mais das dinâmicas populares e dos processos de humanização do que os modelos de transmissão de conhecimento formais entre professor e aluno, do professor para o aluno e as hierarquizações de conhecimentos e conceitos, que na forma verticalizada e monológica, resultou na formalização da crítica por Paulo Freire como educação bancária (FREIRE, 2011).

\section{O LÓCUS DO SABER E O LÓCUS DA ESCOLA}

De maneira geral o que se compreende por aprendizagem e ensino está associado à experiência escolar, na maioria das vezes, e desta forma tudo que se refere à aquisição de novos conhecimentos se resumiria aos domínios da escola. Nesse tipo de educação o enfoque está nos conhecimentos historicamente sistematizados, regulados pela legislação, pelas políticas econômicas que estão vigorando historicamente conforme analisado por Ponce (1991). Uma interpretação possível é que por essa concepção está atrelada ao conceito de educação formal como se não existissem outras possibilidades de educação. Outra interpretação possível provém de Saito (2003), por ocasião de sua crítica à mudança do nome do evento tradicional de Escola de Verão de Investigação-Ação Educacional para Escola de Verão de Investigação-Ação Escolar em sua oitava edição: "Para além de 
uma mera restrição temática ou de foco, o "adjetivo" escolar pode ocultar uma visão de sociedade e processos sociais particulares (...). A escola passa a ser vista como um ente social privilegiado em relação às demais instâncias, capaz de promover transformações sociais pela sua qualificação." Dito de outra forma, a ideia redentora da escola, dissociada do sistema social em sua complexidade, é portadora de uma ingenuidade e voluntarismo que reduz o fracasso da ação transformadora à culpabilização do professor considerado mal-qualificado, passando então a pregar, como solução, maior qualificação e mais capacitação do docente. Esse voluntarismo e foco na qualificação técnica (conteúdo e didática) do professor foi visto no período da escola nova de Carl Rogers (1986) e posteriormente, sob outra retórica políticopedagógica, foi retomada por Guiomar Namo de Mello (1985) quando defendeu a competência técnica como pré-condição para o compromisso político. Tal como em Saito (1990), contrapomos à Guiomar a noção de que é com o "crescimento da consciência política e seu compromisso com a escola pública que os professores buscam seu aprimoramento técnico; é na luta real, na participação do movimento, na discussão com seus colegas" que se dá essa "qualificação" profissional (SAITO, 1990, p. 35).

O que queremos, portanto ressaltar é que não se pode isolar a escola do contexto histórico e dos movimentos sociais, sob pena de proceder a uma análise parcial e fragmentada do processo educacional. $O$ fortalecimento da escola enquanto um ente a serviço dos interesses populares passa justamente pela luta para abertura dos muros da escola à comunidade. Tal como as lutas populares pelos serviços de saúde, as reivindicações e pressões sobre o governo em relação ao destino do dinheiro público que proporciona a qualidade e quantidade dos serviços básicos de responsabilidade do Estado (VALLA,1991), as lutas populares pela democratização do acesso à escola passa pela transformação do perfil da escola, em que o contato mais íntimo com os movimentos sociais permite estabelecer uma estreita interface de aderência entre a educação formal e não-formal. Essa maior intimidade também permite fortalecer e revitalizar os processos de educação popular que visam à emancipação e empoderamento dos indivíduos.

Nesse momento é importante também pontuar a necessária distinção entre educação popular e educação não-formal. Se quando pensamos em educação nãoformal lembramos muitas vezes dos movimentos de educação popular, nem toda educação não-formal é popular. $E$ nem toda educação popular tem o interesse 
emancipatório. Muitas vezes, projetos de educação popular são revestidos de um caráter assistencialista e com tom de caridade. $\mathrm{Na}$ compreensão de Valla et al. (2007), dedicado as lutas populares pelos serviços de saúde, a educação popular que vem sendo realizada no país é verticalizada, pois quando as orientações partem de autoridades governamentais, profissionais, professores e outras categorias de mediadores para as classes populares o conhecimento e os saberes populares não são levados em consideração e dessa forma reproduzem o mesmo movimento de dominação por meio dos conhecimentos científicos. Encontramos ainda em Valla (1998) a necessidade de se valorizar e considerar os saberes populares com vistas à emancipação de forma horizontalizada, pois quando se desqualifica o saber popular reforçando a imagem das classes populares na categoria de carente e nula, infantilizando os indivíduos e negando a diversidade existente dentro desses grupos sociais, eles são tornados culpados pelos problemas que os acometem, como os de saúde e suas clássicas relações com o fracasso escolar em que a vítima é caracterizada como culpada, o que mostra a falta de interesse em se empoderar e emancipar os indivíduos das camadas populares. Para Oliveira e Valla (2001) agir em conjunto na luta contra os problemas sofridos pela população é também respeitar desejos e projetos de vida desses grupos, pois é isso que promove o movimento e em última instância as transformações. Esse caráter assistencialista tem muitas vezes marcado as discussões de educação popular, e confundem exercício da cidadania com processos emancipatórios, e a descodificação de situações-limite do cotidiano como simples problema de alfabetização para a leitura do mundo, compreensão das tecnologias e desenvolvimento de destreza manual para geração de renda, no plano individual, numa clara deturpação pela via neoliberal.

$\mathrm{Na}$ década de 90 a Educação Popular da América Latina passou por um importante momento de discussão paradigmática por meio de encontros internacionais que buscavam definições, metodologias, revisão de teorias, estratégias, formação de educadores, marcados por três encontros importantes: primeiro, o Congresso Internacional de Americanistas realizado em Julho de 1988 na Holanda sobre Educação Popular na América Latina; segundo, um seminário em 1990 na Bolívia para fazer uma avaliação crítica da trajetória da Educação Popular e identificar os desafios a serem enfrentados; e terceiro, em 1995 o seminário realizado em Santiago, Chile. Para Gohn (2002), neste último encontro houve um redirecionamento dos objetivos da Educação Popular, pois anteriormente os 
objetivos estavam centrados nas políticas, na estrutura, depois nos indivíduos. E apesar da maior expressividade dos movimentos sociais terem ocorrido nas décadas anteriores, essas discussões reforçam a urgência de pensar o indivíduo para promover processos educacionais.

Esses encontros, e mais a Conferência da UNESCO realizada na Tailândia em 1990 que teve como tema Educação para todos e como foco central a Satisfação das Necessidades Básicas de Aprendizagem, sugerem a constituição de uma nova visão hegemônica de abordagem no indivíduo e nos seus processos cognitivos. Essa nova visão pode guardar correlação com a política neoliberal em favor da minimização do Estado; daí Gohn (2002) ter identificado a desvalorização do foco nas políticas e estruturas.

\section{A INTEGRAÇÃO EDUCAÇÃO FORMAL E EDUCAÇÃO NÃO-FORMAL}

É preciso, pois resgatar a noção de interface entre a educação formal e a educação não-formal como uma alternativa para contemplar as necessidades da educação concebida de maneira mais abrangente para além da educação formal como reivindicada pelos movimentos sociais em décadas passadas e que se estendem a atualidade. Gohn (1997) define campos ou dimensões para Educação não-formal em relação a suas áreas de abrangência sendo esses: aprendizagem política dos direitos dos indivíduos enquanto cidadãos; o segundo, a capacitação dos indivíduos para o trabalho, por meio da aprendizagem de habilidades; o terceiro, a aprendizagem que promova nos indivíduos a possibilidade de se organizarem para a solução de problemas coletivos cotidianos; e o quarto esta ligado a aprendizagem dos conteúdos da escolarização formal, escolar, em formatos e espaços diferenciados.

No que tange a terceira e quarta dimensões colocadas por Gohn encontramos uma estreita relação à proposta da pedagogia problematizadora de Freire (2011). legado de Paulo Freire tem como característica marcante resgatar os oprimidos e excluídos como sujeitos de educação, sem métodos audaciosos ou de alta complexidade, mas na busca de uma sensibilidade pedagógica para promover formação e humanização (GADOTTI, 1997). O que emerge das ideias de Paulo Freire reforça a necessidade de estimular os indivíduos a confrontar as novas informações com a as suas experiências prévias para que possam reelaborar as 
suas impressões de mundo. Esse processo ocorreria então por meio do diálogo, confronto de ideias, de interesses distintos que possam gerar novas formas de pensar os conflitos, novas posturas a partir da construção de consensos. A educação popular apontada tem o diálogo como base do processo pedagógico para construção cooperativa de conhecimento e ao mesmo tempo a construção de individualidades que estejam preparadas para enfrentar a realidade concreta em que estão inseridos.

Nesse sentido, reforçamos as ideias expostas na experiência de Saito (1999) que ao refletir sobre a educação ambiental especificamente dentro da escola pública questiona sobre o conceito de ambiente que efetivamente se trabalha na escola e quais são os problemas ambientais que mobilizam os alunos e o que os levariam a refletir, problematizar e atuar pela melhoria das condições de vida em sociedade. Para tanto, a partir da educação problematizadora de Paulo Freire, o autor relata seu esforço em organizar atividades de ensino que tenham compromisso político do educador com seus alunos os aproximando dos problemas reais por meio de temas que contribuam para compreensão e transformação da sua vida individual e coletiva, ao invés de se deter no que é pré-fixado nos currículos. No ano de 1986 em uma escola municipal do Rio de Janeiro a discussão sobre a campanha contra o emissário submarino que serviria para lançar esgoto na praia da Barra da Tijuca é levada para as aulas de ciências de 5a série, provocativamente, apresentando o slogan da campanha que dizia: "Cocô na praia, não!". Este ponto de partida desencadeou muitos questionamentos sobre lançar o esgoto na praia e suas consequências pelos alunos. Para responder essas questões, os alunos foram orientados a buscar por meio de entrevistas com membros das associações de moradores que estavam protestando contra o emissário e também com profissionais da saúde, além de pesquisa em livros. A partir desses dados, os alunos, juntamente com o professor, puderam relacionar os problemas relatados aos conhecimentos sistematizados no campo da biologia como ciclos biogeoquímicos, decomposição, doenças de veiculação hídrica, etiologia e sintomatologia, e também fundamentos físico-químicos do emissário. Dentro desse contexto, emergem por parte dos alunos dúvidas sobre como acabar com esgoto a céu aberto na comunidade carente de infra-estrutura e sobre as obras necessárias de saneamento do local de responsabilidade do Estado. A ação pedagógica desenvolvida focou na importância de se relacionar o direito à saúde como algo inalienável do cidadão e conduziram-se 
as discussões de modo a esclarecer esses princípios de cidadania, acoplado à alfabetização científico-tecnológica sobre o tema em questão. O autor relata ainda que coincidentemente houve uma manifestação dos moradores que barraram estradas e o acesso à escola, como meio de protesto contra a falta de saneamento básico. Os alunos aderiram ao movimento, o que leva à reflexão sobre o papel da consciência política ancorada no conhecimento científico-tecnológico. Em outras palavras, a articulação entre a razão instrumental e o interesse emancipatório, na visão de Habermas (1972). Pouco tempo depois, as obras de saneamento foram iniciadas pelo governo. Para o autor independente do resultado concreto da ação coletiva a participação dos alunos na manifestação e aproximação, ou seja, abertura dos muros da escola a situações problema da comunidade representa "o papel do conhecimento e da ação transformadora no modo de vida e das relações sociais" (SAITO, 1999, p.50). Ainda foi ressaltada a análise do surgimento da consciência prática que acompanharia esse tipo de prática pedagógica, a práxis, num profundo processo de conscientização educando-educador. Pois, além do fato de que "O trabalho pedagógico na escola permitiu, desta forma, despertar uma consciência crítica e ativa (SAITO, 1999, p.51)" a tomada de consciência na luta coletiva também educa o professor que tem a oportunidade de romper gradativamente com os valores ideológicos semeados pela classe dominante que na maioria das vezes paralisa e não permite pensar a realidade de forma complexa. Podemos dizer que o agir teórico ou "uma consciência prática" (SAITO, 1999, p.52) também forma o professor e o prepara para cada vez mais para trabalhar esse tipo de situaçãoproblema.

Propomos, assim, pensar nos indivíduos na sua integralidade levando em consideração os processos de humanização. Para tanto, a articulação entre a educação formal e educação não-formal representam um caminho fértil para promover o desenvolvimento humano. Com a crise da racionalidade técnica essas outras dimensões ganham importância como produtoras de conhecimento quando surge abertura para valorizar e reconhecer novos saberes como promotores de novas aprendizagens. A educação não-formal pode potencializar o processo de aprendizagem, complementando-o com outras dimensões que não tem muito espaço nas estruturas curriculares. E como visto anteriormente o contato com os movimentos sociais e as bases da educação não-formal para análise de situaçõesproblema advindas da realidade concreta mostra que a escola enquanto lócus do 
saber sistematizado pode funcionar também como instrumentalizadora dos debates e ações sociais. É nesta perspectiva que o material didático Probio-Educação Ambiental (Probio-EA - material disponível em http://www.ecoa.unb.br/probioea/) foi desenvolvido, procurando trazer para o universo escolar a realidade dos conflitos socioambientais como pontos de partida para problematização sob a égide do par codificação-descodificação, apontando os fundamentos científico-tecnológicos envolvidos tanto na compreensão dos conflitos socioambientais como no entendimento da eficácia das ações positivas efetivamente em curso para solucionar esses mesmos conflitos (SAITO, 2012 e 2013; SAITO et al., 2008 e 2012). Numa perspectiva semelhante, conforme Graebner (2009), a partir de uma verbalização de professores de uma escola rural de que achavam que os seus alunos eram desnutridos, desenvolveu-se um conjunto de ações em que a escola funcionou como um lócus de investigação das condições nutricionais dos escolares com participação da comunidade envolvendo o poder público. Neste trabalho, foi possível impulsionar junto aos docentes a percepção das interdependências que existem entre as muitas disciplinas escolares, por meio de um planejamento coletivo em torno do tema "fome e segurança alimentar" levando-os a compreender tanto as práticas alimentares dos alunos e suas famílias como suas próprias práticas docentes sobre o tema.

\section{CONSIDERAÇÕES FINAIS}

Diante do exposto, é necessário que se faça da escola um espaço de transformação e que as escolas funcionem como centros de referência nas suas regiões de influência. Há uma dívida da escola com a sociedade no sentido de cumprir os desígnios pelos quais os movimentos populares lutaram: a escola a serviço dos interesses da coletividade. Para tal, a escola precisa se despir da roupagem de escola de conteúdos universais didaticamente organizados para uma escola que efetivamente represente um lócus onde o saber sistematizado possa ser alcançado pelos populares para ajudá-los a entender e transformar o mundo, e não como tem se comportado tradicionalmente como portadora de uma cultura escolar que ainda representa uma "inclusão excludente" nas palavras de Gohn (2006). Ou seja, defende-se um saber problematizado a serviço do interesse emancipatório.

A forma de alcançar esse objetivo é aproximando a escola dos movimentos populares e suas lutas, fazendo com que a escola se debruce sobre a realidade que 
a cerca, e que, portanto, não separe em pólos em que a escola seja apenas o local de busca do saber (desinteressado) e que os movimentos sociais sejam os locais de ação. Superando essa fragmentação, não cabe também a visão ingênua de que a escola deva assumir o papel redentor e os movimentos sociais o papel educador de massas, mas tão somente, uma integração entre esses dois processos, tal que um alimente o outro com inspiração, enraizamento, compromisso ético, interesse emancipatório e razão instrumental.

\section{REFERÊNCIAS BIBLIOGRÁFICAS}

ALTHUSSER, L. Ideologia e Aparelhos Ideológicos do Estado. 3. Ed. Lisboa: Editorial Presença/Martins Fontes, 1980.

ARROYO. M. G. Pedagogias em movimento - o que temos a aprender dos Movimentos Sociais? Currículo sem Fronteiras (Online), v. 3, n. 1, p. 28-49, Jan./Jun. 2003.

BRASIL. Lei Federal n. 9.394/96, Lei de Diretrizes e Bases da Educação Nacional.1996.

FERNANDES, F. A democratização do Ensino. In: BARROS, R. S. M. (Org.). Diretrizes e Bases da Educação Nacional. São Paulo: Pioneira, 1960. p. 154-165.

FREIRE, P. Pedagogia do Oprimido. 50. Ed. Rio de Janeiro: Paz e Terra, 2011.

GADOTTI, M. Lições de Freire. Revista da Faculdade de Educação, São Paulo, v. 23, n. 1-2, 1997. Disponível em: $<$ http://dx.doi.org/10.1590/S010225551997000100002>.

GRAEBNER, I. T.; Souza, E. M. T.; Saito, C. H. Action-research and Food and Nutrition Security: A school experience mediated by conceptual graphic representation tool. International Journal of Science Education, v.3, n.6, p.809827.2009. DOI: $10.1080 / 09500690701885646$

GOHN, M. G. Educação popular na América Latina no novo milênio: impactos do novo paradigma. ETD - Educação Temática Digital, Campinas, v. 4, n. 1, p. 53-77, dez. 2002. Disponível em: <http://www.bibli.fae.unicamp.br/etd/AR03.pdf>. Acesso em 29 de Abr. de 2013.

GOHN, M. G. Educação não-formal, participação da sociedade civil e estruturas colegiadas nas escolas. Revista Ensaio-Avaliação e Políticas Públicas em Educação, Rio de Janeiro, v. 14, n. 50, p. 11-25, 2006.

HABERMAS, J. Knowledge and human interests. Boston: Beacon Press, 1972. 
KOWARICK, L. A espoliação urbana. Rio de Janeiro: Paz e Terra, 1980.

MELLO, G. N. Magistério de $1^{\circ}$ grau: da competência técnica ao compromisso político. São Paulo: Cortez; Autores Associados, 1985.

OLIVEIRA, R. M.; VALLA, V. V. As condições e as experiências de vida de grupos populares no Rio de Janeiro: repensando a mobilização popular no controle da dengue. Cadernos de Saúde Pública, Rio de Janeiro, v. 17 (Suplemento), p.77-88, 2001.

PONCE, A. Educação e luta de classes. São Paulo: Cortez; Autores Associados, 1991.

ROGERS, C. Liberdade de Aprender em Nossa Década. 2. Ed. Porto Alegre: Artes Médicas, 1986.

SAITO, C. H. Ciência Viva: para perder o medo e criar. 1990. Dissertação (Mestrado em Educação) - Programa de Pós-Graduação em Educação, Universidade Federal Fluminense, Niterói, 1990.

. Escola de Verão de Investigação-ação: escolar ou educacional? In: VIII Escola de Verão de Investigação-ação escolar, 2003, Camboriú-SC. Atas da VIII Escola de Verão de Investigação-Ação Escolar - Ciência e Tecnologia na formação de professores. Camboriú-SC: CAC/UFSC, 2003.

. Os desafios contemporâneos da Política de Educação Ambiental: dilemas e escolhas na produção do material didático. In: RUSCHEINSKY, A. (Org.). Educação Ambiental: Abordagens Múltiplas. 2. Ed. Porto Alegre: Artmed, 2012. p. 250-266.

Environmental Education and Biodiversity concern: beyond the ecological literacy. American Journal of Agricultural and Biological Sciences, v. 8, n. 1, p. 12-27, 2013.

SAITO, C.H.; BASTOS, F.P.; ABEGG, I. Teorias-guia educacionais da produção dos materiais didáticos para a transversalidade curricular do meio ambiente do MMA. Revista Iberoamericana de Educación (Online), v. 45, p. 1-10, 2008. Disponível em: <http://www.rieoei.org/expe/1953Saito.pdf>.

SAITO, C. H., LUNARDI, D. G., PORTO, C. B., GERMANOS, E., SAITO, I. T., BARBOSA, R.G. Imagem e Território como ponto de partida para uma educação ambiental dialógico-problematizadora. Espaço e Geografia, v.15, p. 491-516, 2012.

TEIXEIRA, A. Educação não é privilégio. Rio de Janeiro: Editora UFRJ, 1999.

VALLA. V. Educação, saúde e cidadania: investigação científica e assessoria popular. Cadernos de Saúde Pública, Rio de Janeiro, v. 8, n. 1, Jan./Mar. 1992.

Sobre participação popular: uma questão de perspectiva. Cadernos de Saúde Pública, Rio de Janeiro, v. 14 (sup. 2), p. 7-18, 1998. 
VALLA. V.; GUIMARÃES, M. B.; LACERDA, A. Construindo a proposta de educação e saúde. Cadernos de educação popular e saúde, 2007. Disponível em: $<$ http://portal.saude.gov.br/portal/arquivos/pdf/caderno de educacao popular e sau de.pdf>. 